\title{
Experiência de reorganização da APS para o enfrentamento da COVID-19 em Florianópolis
}

\author{
João Paulo Mello da Silveira, Ronaldo Zonta
}

\section{RESUMO}

O município de Florianópolis, Santa Catarina, tem se destacado ao longo dos anos no investimento em Atenção Primária à Saúde (APS) e desenvolvimento de experiências de teleatendimento. Isso permitiu que a rede se organizasse de uma maneira muito rápida para atuar frente à pandemia da Covid-19. A aposta foi reforçar os atributos da APS para o enfrentamento à pandemia, manter as unidades abertas, reforçar a APS como porta de entrada, fortalecer e privilegiar o teleatendimento, reorganizar os fluxos na unidade, evitar as aglomerações nos serviços, garantir os EPI para os profissionais da saúde e produzir material técnico para orientar essas ações. Este artigo apresenta as respostas de Florianópolis ao contexto da pandemia da COVID-19.

Palavras-chave: Atenção Primária à Saúde; COVID-19; Pandemia.

\section{ABSTRACT}

The municipality of Florianópolis, Santa Catarina, has been noteworthy over the years in investing in Primary Health Care and developing tele-service experiences. This allowed the network to organize itself in a very fast way to act in the face of the COVID19 pandemic. The focus was to reinforce the attributes of the PHC to face the pandemic, to keep the units open, to reinforce the PHC as a gateway, to strengthen and privilege the tele-service, to reorganize the flows in the unit, to avoid the agglomerations in the services, to guarantee the individual protection equipment for health professionals and produce technical material to guide these actions. This article presents Florianópolis' responses to the context of the COVID-19 pandemic.

Keywords: Primary Health Care; COVID-19; Pandemic.
Revista da Rede APS 2020

Publicada em: 09/06/2020

DOI:10.14295/aps.v2i2.122

João Paulo Mello da Silveira

(Gerente de Atenção Primária à

Saúde de Florianópolis,

Florianópolis, SC, Brasil)

Ronaldo Zonta

(Departamento de Gestão da Clínica da Secretaria Municipal de Saúde de Florianópolis, Florianópolis, SC, Brasil)

Correspondência para: João Paulo Cerqueira gap.sms.pmf@gmail.com

Ronaldo Zonta ronaldozonta@gmail.com

A Editoria Científica agradece à Diana Ruiz (ISC/UFBA) pelo apoio à edição deste artigo. 


\section{A OpÇÃo PELO TELEATENDIMENTO E}

\section{TELE-MONITORAMENTO}

Mesmo antes do início da pandemia no Brasil, Florianópolis estava organizando o lançamento de um serviço de atendimento pré-clínico denominado "Alô saúde Floripa", tendo sido entregue às equipes de saúde da família smartphone, chip pós-pago e acesso à plataforma WhatsApp Business para facilitar a comunicação com a população. Com a chegada da pandemia esse serviço pré-clínico foi fortalecido e os números de contato do WhatsApp das equipes divulgados amplamente na população. Neste serviço, o usuário, ao ligar, é direcionado para a equipe na qual está cadastrado sendo também fornecido o contato de celular de WhatsApp da equipe. Para as pessoas sem cadastro foi implementado o cadastro online. Em maio de 2020 estão em funcionamento 49 canais de WhatsApp (um para cada unidade) para demandas administrativas e 150 números para as equipes (um para cada equipe) para contato direto com os usuários, além do 0800 "Alô Saúde Floripa".

A partir a ligação do usuário ao "Alô Saúde Floripa" ou diretamente para a equipe na qual está cadastrado, é tomada a decisão (baseada em protocolos) sobre se a pessoa vai ser atendida por tele-consulta ou de maneira presencial na unidade. A orientação tem sido privilegiar o teleatendimento para todos os pacientes sintomáticos respiratórios e também para as outras demandas.

As equipes também foram orientadas a realizar busca ativa telefônica ou através de WhatsApp de usuários em situações clínicas de maior risco ou vulnerabilidade (gestantes de mais risco, usuárias para primeira consulta de puericultura, pacientes crônicos já conhecidos das equipes, usuários hipertensos ou diabéticos descompensados). Aqui, e preparando para o eventual enfrentamento de possíveis novas ondas da pandemia, a orientação tem sido ligar para os pacientes com risco moderado para fazer o atendimento à distância do que for possível e o atendimento presencial do restante dos pacientes.

Para tornar as tele-consultas mais resolutivas, além do prontuário eletrônico implementado em Florianópolis, foram estruturadas outras ferramentas e procedimentos, tais como: criação de normativa para que a rede de farmácias aceite as receitas de medicamentos comuns e antibióticos feitas por vídeo chamada; estabelecimento de acordo com laboratórios para que aceitem o pedido em formado eletrônico virtual da requisição; e implantação de código de barras bidimensional escaneável para fornecimento de atestados médicos. As equipes também se organizaram para levar os medicamentos nos domicílios das pessoas hipertensas ou diabéticas com dificuldade para ir à farmácia e pegar suas medicações.

O tele-monitoramento de casos, por sua vez, foi feito pela vigilância epidemiológica e quando os casos de infecção começaram a se multiplicar, ele passou a ser capilarizado para toda a APS. Independente se o caso provável é notificado pela rede municipal ou pela rede privada, o telemonitoramento de casos confirmados e seus contatos e de casos prováveis é conduzido pelas equipes de cada território onde a pessoa mora. Ou seja, feito pelos profissionais da equipe multiprofissional de APS territorializada e pelos 50 médicos e 30 enfermeiros residentes que já atuavam. Esse processo foi reforçado com profissionais da equipe de saúde bucal e médicos da média complexidade e policlínicos onde foram suspensos todos os atendimentos eletivos. A equipe responsável pelo território faz contato telefônico com a pessoa, faz o telemonitoramento e se a pessoa relatar algum agravamento, alguma demanda, pode-se ofertar uma tele-consulta agendada ou imediatamente caso o atendimento seja feito por médico ou enfermeira.

Para tal atendimento, foram testadas várias ferramentas. Inicialmente foi usada uma planilha compartilhada, posteriormente o prontuário eletrônico e neste momento está 
sendo estudada a implementação de um programa de computador para simular um ser humano na conversação com as pessoas, ficando a equipe somente na busca dos casos que não responderam ou que têm algum fator de risco ou vulnerabilidade.

\section{REORGANIZANDO OS FLUXOS NAS} UNIDADES DE APS

As 149 unidades de APS de Florianópolis continuaram abertas e visando evitar aglomerações, foi realizada reorganização do fluxo de pacientes. Na frente de cada unidade foi montada uma barreira física com um profissional equipado com EPI para recebimento dos usuários. Nas unidades onde foi possível se estabeleceram duas portas: uma para os sintomáticos respiratórios e outra para o resto das demandas. O profissional da entrada orienta os usuários nessa separação. Dessa maneira, os pacientes sintomáticos respiratórios e os que consultam por outras necessidades e são assintomáticos tentam se manter ao máximo possível separados. Além disso, é feita desinfeção constante das unidades de APS.

\section{ATUAÇÃO DOS PROFISSIONAIS}

\section{Agentes Comunitários de Saúde (ACS)}

O processo de trabalho do ACS já estava sendo modificado antes da eclosão da pandemia da COVID-19. A execução de parte da carga horaria era dentro da unidade, contribuindo com o planejamento da equipe, organização das agendas, atendimento telefônico e respondendo mensagens de WhatsApp dos usuários. As suas ações no território foram restritas à busca ativa dos usuários de maior risco e vulnerabilidade que não conseguiam ser contatados de maneira remota. Com a COVID-19 o ACS ficou principalmente dentro da unidade, desenvolvendo atividades de acolhimento e busca ativa dos usuários de maneira remota não presencial, utilizando suas habilidades para comunicação com as comunidades e sua competência cultural, e em alguns casos faz busca ativa no território de casos que não estão podendo ser localizados para monitoramento. Neste momento, está sendo discutida a possibilidade e viabilidade de que o ACS faça busca e rastreamento dos sintomáticos respiratórios no território.

\section{Equipe de Saúde Bucal e Núcleo Ampliado de Saúde da Família e Atenção Básica}

(NASF)

Foram suspensos todos os atendimentos em saúde bucal não emergenciais, devido à geração de partículas ou aerossóis. Está sendo discutida a possibilidade de teleatendimento em saúde bucal para orientações ou talvez para fazer a primeira consulta do recém-nascido e atenção de gestantes que já tenham sido atendidas e cuja situação seja conhecida pela equipe previamente. As especialidades em saúde bucal também têm realizado matriciamento. O NASF, por sua vez, tem possibilitado aos profissionais que entrem em contato com a população através de teleatendimento e matriciamento com as equipes de APS.

\section{Testagem}

Foram adquiridos testes rápidos pela gestão da APS e estão disponíveis em todos os 49 centros de saúde e também em serviço drive-thru de testagem, utilizado em casos onde é necessário testar muitas pessoas. Se uma pessoa tiver sintomas faz menos de 7 dias, pode ser feita a coleta de sangue para exame da Proteína CReativa (PCR) no domicílio. Se os sintomas são superiores a 7 dias, o paciente é orientado a procurar a unidade de saúde e fazer o teste rápido. Os contatos de um caso positivo são encaminhados para o drive-thru e começam a ser encaminhados para as equipes do território dessa pessoa. 


\section{ISOLAMENTO SOCIAL E ARTICULAÇÃO}

\section{INTERSETORIAL COM A VIGILÂNCIA EM}

\section{SAÚDE E SOCIEDADE CIVIL}

Sobre as medidas de distanciamento e isolamento social, a gestão central do município esteve aberta a ouvir o corpo técnico e estabelecer as medidas distanciamento social e uso de máscara (inclusive caseira) para todos. A APS apoia a divulgação de informações de saúde e cuidados usando o WhatsApp das equipes, sendo importante estratégia para mitigar notícias falsas sobre a pandemia. A articulação intersetorial e com a sociedade civil vem sendo feita juntamente com a Secretaria de Assistência Social e projeto "Somar Floripa", rede de organizações voluntárias. A partir dessa parceria tem se conseguido organizar a distribuição de cestas básicas para a população carente; adaptar hotel para acolher os moradores de rua, que não tinham como fazer o isolamento social, no qual também participou o setor privado; e mobilizar da comunidade para ajudar idosos que estão em casa e precisam fazer compras e mercados e não podem sair devido à situação de distanciamento social.

Também, foi feita uma parceria com algumas ONGs que estão contribuindo na entrega de medicamentos para pessoas que vivem com vírus da imunodeficiência humana (HIV) e tinham problemas para pegar a medicação, pela suspensão do transporte público. O Departamento de Gestão de Clínica de Florianópolis tem produzido materiais técnicos (sobre uso de EPI, quando fazer ou não vídeo consultas, protocolos para vídeo consultas para diversas doenças, etc.) em diversos formatos e compartilhado também pelo WhatsApp.

Destaca-se ainda a parceria com a vigilância sanitária e a guarda municipal, que tem reforçada a vigilância nos estabelecimentos públicos e privados. Nos supermercados existem protocolos importantes para evitar o contágio (uso obrigatório de máscara, medição da temperatura antes de entrar, com a não entrada de pessoas com febre, desinfeção de mãos, limite na quantidade de pessoas que podem ingressar no mesmo momento e marcas no chão para evitar aglomerações nas filas). Além disso, está mantida a barreira sanitária no aeroporto, isto é, todas as pessoas que chegam à cidade devem assinar o termo de restrição. Se tiverem sintomas são avaliados por uma equipe, podendo ser testadas nesse mesmo momento (teste rápido) ou programada coleta para PCR no domicílio (segundo a evolução temporal dos sintomas) e a pessoa fica em isolamento social enquanto se confirma ou descarta a infeção por COVID-19.

\section{ProteÇÃo E CUIDAdO doS PROFISSIONAIS DE SAÚDE}

Em 13 de março de 2020 observou-se quantidade insuficiente de EPI para o enfrentamento à COVID-19. Houve um esforço para adquirir mais EPI e dessa maneira garantir que todas as unidades ficassem abertas. Os profissionais são testados sempre que apresentem sintomas respiratórios, ainda que não cumpram todos os critérios estabelecidos de infecção. Foram notificados até este mês de maio quatro profissionais da saúde da rede municipal como casos prováveis de COVID-19, dos quais um foi confirmado (contágio no contexto familiar através de um caso importado). Nos casos prováveis foi realizada desinfeção das unidades e foram retomados os atendimentos $24 \mathrm{~h}$ depois, após avaliação dos critérios de contato próximo. Foram afastados profissionais de saúde que estivessem em grupos de risco (maiores de 60 anos ou com alguma comorbidade de risco). Isso ocasionou uma perda de pessoal qualificado e alguns profissionais da média complexidade foram realocados para dar suporte na APS.

\section{CONSIDERAÇõES FINAIS}


A partir da experiência de Florianópolis observase como a pandemia da COVID-19 acelerou mudanças no processo de trabalho em saúde com a incorporação de tecnologias de comunicação (telefone, internet, WhatsApp, vídeo chamada) na APS e em geral em toda a rede atenção no SUS. A proposta de Florianópolis tem sido utilizar as tecnologias de comunicação para atenção em saúde e continuar com o trabalho no território, com foco nos pacientes de risco, que estão sem contato, que não respondem as ligações, que não usam tecnologias (idosos) ou estão em situações de grande vulnerabilidade como as pessoas em situação de rua. É importante lembrar das limitações das ferramentas tecnológicas, sendo necessário fazer adaptações de acordo às características do território e da população.

Neste caso também se destacam as medidas de distanciamento social que têm permitido ganhar tempo para a reorganização da APS e de toda a rede de atenção no SUS. De forma geral, estas ações têm contribuído ao controle do número de casos e têm evitado (até o momento) um desborde da capacidade hospitalar. A experiência da APS e da saúde em Florianópolis demonstra preparo para as novas ondas que virão e para o possível aumento de casos que pode acontecer depois da diminuição gradual das medidas de isolamento social das últimas semanas, influenciadas pelas pressões econômicas. 


\section{NOTAS E REFERÊNCIAS}

Gerência de Vigilância Epistemológica de Florianópolis, Brasil, 2020 - Disponível em < https://sites.google.com/view/gerve/dmcae/agravos/covid-19?authuser=0 >

Rede de Pesquisa em Atenção Primária à Saúde, Brasil 2020 - Disponível em < https://redeaps.org.br/2020/04/30/iniciativas-da-sms-aps-florianopolis-para-enfrentamento-da-covid$19 />$ 